\title{
A genome-wide linkage analysis of alcoholism on microsatellite and single-nucleotide polymorphism data, using alcohol dependence phenotypes and electroencephalogram measures

\author{
Chun Zhang1, Simon Cawley², Guoying Liu ${ }^{3}$, Manqiu Cao1, Harley Gorrell ${ }^{3}$ \\ and Giulia C Kennedy*1
}

\begin{abstract}
Address: ${ }^{1}$ Genomics Collaborations Department, Affymetrix, Santa Clara, CA, 95051, USA, ${ }^{2}$ Department of Algorithms and Data Analysis, Affymetrix, Santa Clara, CA, 95051, USA and ${ }^{3}$ Bioinformatics Department, Affymetrix, Emeryville, CA, 94608, USA

Email: Chun Zhang - chun_zhang@affymetrix.com; Simon Cawley - simon_cawley@affymetrix.com;

Guoying Liu - guoying_liu@affymetrix.com; Manqiu Cao - manqiu_cao@affymetrix.com; Harley Gorrell - harley_gorrell@affymetrix.com; Giulia C Kennedy* - giulia_kennedy@affymetrix.com

* Corresponding author
\end{abstract}

from Genetic Analysis Workshop 14: Microsatellite and single-nucleotide polymorphism

Noordwijkerhout, The Netherlands, 7-10 September 2004

Published: 30 December 2005

BMC Genetics 2005, 6(SuppI I):SI7 doi:10.1 I86/I47I-2I56-6-SI-SI7

\begin{abstract}
The Collaborative Study on the Genetics of Alcoholism (COGA) is a large-scale family study designed to identify genes that affect the risk for alcoholism and alcohol-related phenotypes. We performed genome-wide linkage analyses on the COGA data made available to participants in the Genetic Analysis Workshop I4 (GAW 14). The dataset comprised I,350 participants from I43 families. The samples were analyzed on three technologies: microsatellites spaced at $10 \mathrm{cM}$, Affymetrix GeneChip ${ }^{\circledR}$ Human Mapping $10 \mathrm{~K}$ Array (HMA IOK) and Illumina SNP-based Linkage III Panel. We used ALDXI and ALDX2, the COGA definitions of alcohol dependence, as well as electrophysiological measures TTTHI and ECB2I to detect alcoholism susceptibility loci. Many chromosomal regions were found to be significant for each of the phenotypes at a $p$-value of 0.05 . The most significant region for ALDXI is on chromosome 7, with a maximum LOD score of 2.25 for Affymetrix SNPs, I.97 for Illumina SNPs, and 1.72 for microsatellites. The same regions on chromosome 7 (96-106 cM) and 10 (I49-176 cM) were found to be significant for both ALDXI and ALDX2. A region on chromosome 7 (II $2-153$ cM) and a region on chromosome 6 (169-185 CM) were identified as the most significant regions for TTTHI and ECB2I, respectively. We also performed linkage analysis on denser maps of markers by combining the SNPs datasets from Affymetrix and Illumina. Adding the microsatellite data to the combined SNP dataset improved the results only marginally. The results indicated that SNPs outperform microsatellites with the densest marker sets performing the best.
\end{abstract}

\section{Background}

Alcoholism is a complex disorder in which multiple genes may contribute to the risk [1]. To address this complexity, the Collaborative Study on the Genetics of Alcoholism (COGA) researchers designed a large-scale family study and collected multiple alcoholism and alcohol-related phenotypes from the participants.

ALDX1, the primary COGA definition of alcohol dependence, requires a person to meet both DSM-III-R criteria and the Feighner criteria [1,2]. Linkage analyses using 
ALDX1 have provided evidence of linkage on chromosome 1,2 , and $7[3,4]$. Highly heritable electrophysiological variables, such as electroencephalography (EEG) and event-related potentials (ERPs), have been used to identify the genes that affect brain activities related to alcoholism. Data from the Eyes Closed Resting EEG experiment (ECB21) have revealed a strong linkage on chromosome $4[5,6]$. In further studies, the far frontal left side channel measure extracted from the target case of the Visual Oddball experiment for 4 electrode placements (TTTH1) revealed a strong linkage on chromosome 7 [7]. In these studies a 10-cM map of microsatellites was used for the initial scan. The recent addition of singe nucleotide polymorphisms (SNPs) within these linkage regions has improved the resolution of the mapping results $[1,7]$.

The microsatellite-based screening approach has been used successfully for mapping Mendelian diseases. However, this technique has been proven to be unreliable for complex genetic diseases $[8,9]$. It has been suggested that a 1-2 cM map of moderately polymorphic biallelic markers would be more powerful than a 5-10 cM map of microsatellite screening sets [10]. If that is the case, the recently developed, high-density oligonucleotide arraybased, whole-genome sampling analysis approach [11] should provide an ideal set of genotype data for a whole genome scan.

The COGA dataset provided to participants at GAW14 included data from 1,350 participants from 143 families. The genotype dataset included data produced by a $10-\mathrm{cM}$ map of microsatellites, Affymetrix GeneChip ${ }^{\circledR}$ Human Mapping $10 \mathrm{~K}$ Array (HMA10K), and Illumina SNP-based Linkage III Panel. To identify susceptibility regions for alcoholism, we performed a genome-wide multipoint linkage analysis using alcohol dependence phenotypes ALDX1, ALDX2 (diagnosed by DSM-IV criteria), and quantitative traits TTTH1 and ECB21. The performance of microsatellites, Affymetrix HMA10K Array, and Illumina Linkage III Panel were compared in terms of information content, identified linkage regions and the 1-LOD support interval of the regions.

\section{Methods \\ Map construction}

The 10-cM microsatellite maps contained 328 microsatellites of which 309 have unique locations on the deCode high-resolution genetic maps. To map the SNPs, we first obtained the physical locations from build 34 of the human genome dbSNP database at the National Center for Biotechnology Information (NCBI). We then interpolated the genetic map locations using the microsatellite with unique physical locations in deCode genetic maps. 11,050 Affymetrix SNPs and 4,700 Illumina SNPs with unique sex-averaged genetic map locations were used in our study. We also created an even denser map of markers by combining Affymetrix and Illumina SNPs (Comb2). In addition, we combined Affymetrix and Illumina SNPs with the microsatellite data (Comb3) to determine the contribution of microsatellite markers.

\section{Genotype error detection}

The datasets were prepared with PEDCHECK [12] to remove Mendelian inconsistencies. A small number of erroneous genotypes can reduce the power of linkage analysis [13-15]. We therefore used MERLIN [16] to eliminate the genotypes with unlikely recombination patterns ( $0.39 \%$ for microsatellites, $0.16 \%$ for Affymetrix SNPs, $0.13 \%$ for Illumina SNPs).

\section{Linkage analysis}

Information content (IC) measures how much of the inheritance information can be extracted from available genotype data. It closely predicts the power of a map to detect linkage [10]. We used MERLIN to calculate IC at every marker locus.

Alcohol dependence phenotypes ALDX1 and ALDX2 include five categories: no information; pure unaffected; never drank; unaffected with some symptoms; affected. We treated "never drank" as "no information", and combined "pure unaffected" and "unaffected with some symptoms" as "unaffected." We performed nonparametric linkage (NPL) analysis based on the identity-by-descent (IBD) sharing among affected individuals in a pedigree. We used MERLIN to calculate NPL ${ }_{\text {all }}$ [17] and the corresponding nonparametric LOD scores based on the linear model [18]. NPL scores are generally regarded as conservative $[17,18]$. The nonparametric LOD scores give more accurate $p$-values and can be used to construct 1-LOD support intervals [9]. For this reason we used the nonparametric LOD scores in our analysis. We chose significance level 0.05 to report linkage regions.

We conducted variance components analyses on the log transformed quantitative traits TTTH1 and ECB21, adjusting for age and sex. Heritability of the traits and the LOD scores at every marker locus were calculated by using MERLIN.

\section{Computational implementation}

MERLIN is a software package designed for dense genetic maps in pedigree data. It efficiently implements the Lander-Green algorithm [19] by using sparse binary trees to represent gene flow. We modified the tree structure in the source code of MERLIN and adjusted different compilation options to improve efficiency on highly dense maps and extensive pedigrees by $25 \%$ on a 32 -bit UNIX machine and $50 \%$ on a 64 -bit UNIX machine. 
Table I: Summary of the maps

\begin{tabular}{lccl}
\hline Map & Number of markers & Mean spacing (SD) (in cM) & Mean heterozygosity (range) \\
\hline Microsatellite & 309 & $10.820(8.650)$ & $0.715(0.134-0.922)$ \\
Affymetrix & 11,049 & $0.328(0.619)$ & $0.340(0-0.720)$ \\
Illumina & 4,700 & $0.786(1.182)$ & $0.440(0.100-0.550)$ \\
Comb3 & 16,058 & $0.230(0.405)$ & N/A \\
Comb2 $^{b}$ & 15,749 & $0.234(0.414)$ & N/A \\
\hline
\end{tabular}

aComb2: combined Affymetrix and Illumina SNP data.

bComb3: combined microsatellite markers, and Affymetrix and Illumina SNP data.

\section{Results}

\section{Summary of the maps}

The summary statistics for the data are shown in Table 1. Among the three data sets, Affymetrix SNPs have the highest and the most uniform density across the genome. Due to the sparseness of the microsatellites, there is only slight difference in density between the combined SNPs and the combined SNPs and microsatellites.

\section{Information content}

Microsatellites had the lowest mean and highest standard deviation (SD) of genome-wide IC due to the limited coverage of the genome (Table 2). With the densest map, Affymetrix SNPs produced the highest mean and lowest $\mathrm{SD}$ as well as a lowest inter-quartile range and most narrow range of IC. This indicates a uniform and robust distribution of IC across the genome. The same trend remained for the combined map with microsatellites and SNPs (Comb3). The combined SNPs data (Comb2) show similar IC compared with Comb3 (Table 3). These results show that density plays a key role in extracting inheritance information from the available genotype data.

\section{Linkage analysis with alcohol dependence phenotypes ALDXI and ALDX2}

Both ALDX1 and ALDX2 phenotypes showed significant linkage on chromosome 7 (96-106 cM) and chromosome $10(149-176 \mathrm{cM})$ in all the datasets. In the SNP datasets, both phenotypes detected the same region on chromosome X (30-46 cM), although the LOD scores for ALDX2 were much less significant (Table 4, Table 5).
Our analyses also detected linkage regions unique to each phenotype. For ALDX1, linkage was detected on chromosome $2,7,10$, and 11 (Table 4) in all of the data sets. Additional linkage regions on chromosome 1, 6, 9, 12, 13, 18 , and $\mathrm{X}$ were detected in the SNP datasets. Consistent with previous literature $[3,4]$, the most significant linkage region in the combined data (Comb3) was located on chromosome 7 (Figure 1). In the Affymetrix panel, the highest maximum LOD score was 2.25 at $100.871 \mathrm{cM}$ (Table 4). The 1-LOD intervals for this linkage region (Affymetrix: $6.551 \mathrm{cM}$; Illumina: $9.557 \mathrm{cM}$; microsatellites: $26.80 \mathrm{cM}$ ) revealed significant difference between microsatellites and SNPs. An even higher maximum LOD score of 2.52 at $101.049 \mathrm{cM}$ with a narrower 1-LOD interval 3.647 (Figure 1) was achieved with a denser map in the combined datasets (Comb3). On chromosome 1 and 2 we found linkage regions adjacent to the significant regions reported in $[3,4]$ in both SNP datasets. In contrast, we did not find any evidence of linkage to these two regions in the microsatellite data. Analyses using ALDX1 on selected chromosomes of the Comb2 and Comb3 data showed almost identical results.

For ALDX2, linkage regions on chromosome 1 (247-259 $\mathrm{cM}), 7$ (96-106 cM), 10 (141-176 cM), and 17 (30-53 $\mathrm{cM}$ ) were significant at a level of 0.05 in all the three datasets. Other significant regions on chromosome 2, 3, 6, 7, 9,10 , and $\mathrm{X}$ were detected in SNP data sets but were not present in the microsatellite data (Table 5).

Linkage analysis with EEG measures TTTHI and ECB2 I The kurtosis values of the log transformed TTTH1 and ECB2 1 are -0.13 and -0.44 , respectively, indicating no sig-

Table 2: Summary of IC

\begin{tabular}{lccccc}
\hline & Minimum & Maximum & Mean & SD & Interquartile range \\
\hline Microsatellite & 0.3394 & 0.9569 & 0.7937 & 0.0990 & 0.1306 \\
Affymetrix & 0.5239 & 0.9678 & 0.9421 & 0.0258 & 0.0166 \\
Illumina & 0.3765 & 0.9606 & 0.9189 & 0.0289 & 0.0252 \\
Comb3a & 0.7592 & 0.9908 & 0.9707 & 0.015 & 0.0131 \\
\hline
\end{tabular}

aComb3: combined microsatellite marker and both Affymetrix and Illumina SNP data. 
Table 3: Comparison of IC and density for combined data

\begin{tabular}{|c|c|c|c|c|c|c|c|c|}
\hline & \multicolumn{2}{|c|}{ Chr 2} & \multicolumn{2}{|c|}{ Chr 6} & \multicolumn{2}{|c|}{ Chr 7} & \multicolumn{2}{|c|}{ Chr X } \\
\hline & Mean IC (SD) & Spacing (SD) & Mean IC (SD) & Spacing (SD) & Mean IC (SD) & Spacing (SD) & Mean IC (SD) & Spacing (SD) \\
\hline Comb3a & $0.975(0.01)$ & $0.191(0.30)$ & $0.974(0.01)$ & $0.181(0.33)$ & $0.976(0.01)$ & $0.217(0.36)$ & $0.947(0.03)$ & $0.396(0.72)$ \\
\hline Comb2b & $0.958(0.01)$ & $0.196(0.31)$ & $0.957(0.01)$ & $0.184(0.33)$ & $0.956(0.01)$ & $0.225(0.37)$ & $0.931(0.03)$ & $0.407(0.74)$ \\
\hline
\end{tabular}

aComb3: combined data set of microsatellites, Affymetrix and Illumina SNPs.

bComb2: combined data of Affymetrix and Illumina SNPs.

nificant deviation from the normal distribution. Therefore, these trait values were acceptable for use in variance components analysis.

The estimate of heritability, after adjusting for age and sex, is $35.17 \%$ for TTTH 1 . The most significant region on chromosome 7 (112-153 cM: LOD score 1.47 for Affymetrix SNPs, 2.01 for Illumina SNPs, and 2.44 for microsatellites) overlaps with the one reported by Jones et al. [7], but the heritability is lower. The difference in heritability values could be due to different sample structure or different algorithms (Jones et al. [7] performed the variance components analyses using the t-distribution option of SOLAR) used in these two studies.

The estimate of heritability for ECB21 is $55.54 \%$ after adjusting for age and sex. One of the linkage regions on chromosome 4 (58-79 cM: LOD score 1.10 for Affymetrix, 1.25 for Illumina, and 1.40 for microsatellites) over- laps with the highly significant linkage region found in previous studies $[5,6]$. The most significant region is on chromosome 6 (169-185 cM: LOD score 2.18 for Affymetrix, 2.11 for Illumina, and 0.71 for microsatellites).

\section{Discussion}

Based on the COGA data provided to participants at GAW14, we have presented a NPL analysis for alcohol dependence phenotypes ALDX1 and ALDX2, and a variance component analysis for EEG measures TTTH1 and ECB21. Our results confirmed some of the linkage findings in previous studies [3-7]. The increased density of the SNP data extends the number of regions detected and increases the resolution of the linkage results.

In our study, we used a $p$-value of 0.05 as the significance level to report linkage regions. However, in order to define true linkage and explain the inconsistencies among the results of different datasets, it is important to choose a

Table 5: Summary of linkage results for ALDX2

\begin{tabular}{|c|c|c|c|c|c|c|c|}
\hline \multirow[b]{2}{*}{ Chr } & \multirow[b]{2}{*}{ Location (cM) } & \multicolumn{2}{|c|}{ Affymetrix SNPs } & \multicolumn{2}{|c|}{ Illumina SNPs } & \multicolumn{2}{|c|}{ Microsatellite } \\
\hline & & $\operatorname{LOD}(p)$ & $\mathrm{IC} / \mathrm{Chr}$ & $\operatorname{LOD}(p)$ & $\mathrm{IC} / \mathrm{Chr}$ & $\operatorname{LOD}(p)$ & $\mathrm{IC} / \mathrm{Chr}$ \\
\hline \multirow[t]{2}{*}{ I } & $42-44$ & & $0.942(0.02)$ & $0.73(0.03)$ & $0.932(0.02)$ & $0.68(0.04)$ & $0.832(0.07)$ \\
\hline & $247-259$ & $0.81(0.03)$ & & $0.72(0.03)$ & & $0.68(0.04)$ & \\
\hline \multirow[t]{2}{*}{2} & $19-23$ & & $0.948(0.02)$ & $0.86(0.02)$ & $0.934(0.02)$ & $0.75(0.03)$ & $0.845(0.08)$ \\
\hline & $226-247$ & $1.49(0.004)$ & & $1.53(0.004)$ & & & \\
\hline 3 & $90-93$ & $0.99(0.02)$ & $0.947(0.01)$ & $0.70(0.04)$ & $0.938(0.02)$ & & $0.755(0.08)$ \\
\hline 6 & $|7|-189$ & $1.49(0.004)$ & $0.947(0.02)$ & $1.69(0.003)$ & $0.935(0.02)$ & & $0.803(0.09)$ \\
\hline \multirow[t]{4}{*}{7} & $3-9$ & $1.01(0.02)$ & $0.944(0.03)$ & $2.25(0.0006)$ & $0.933(0.02)$ & & $0.898(0.05)$ \\
\hline & $59-60$ & $0.64(0.04)$ & & & & $0.82(0.03)$ & \\
\hline & $96-106$ & 1.22 (0.009) & & $0.85(0.02)$ & & $0.83(0.03)$ & \\
\hline & $108-116$ & $0.99(0.02)$ & & $0.87(0.02)$ & & & \\
\hline 9 & $133-155$ & $1.28(0.008)$ & $0.947(0.02)$ & $1.50(0.004)$ & $0.926(0.02)$ & & $0.782(0.10)$ \\
\hline \multirow[t]{3}{*}{10} & $47-49$ & $0.75(0.03)$ & $0.943(0.02)$ & & $0.924(0.03)$ & & $0.664(0.08)$ \\
\hline & $120-130$ & $1.18(0.01)$ & & $1.33(0.007)$ & & & \\
\hline & $14 \mid-176$ & $1.97(0.0013)$ & & $1.78(0.002)$ & & $0.74(0.03)$ & \\
\hline 12 & $167-172$ & & $0.944(0.02)$ & $0.94(0.02)$ & $0.929(0.03)$ & & $0.816(0.08)$ \\
\hline 17 & $30-53$ & $1.44(0.005)$ & $0.922(0.05)$ & $1.39(0.006)$ & $0.914(0.03)$ & $1.83(0.002)$ & $0.694(0.08)$ \\
\hline$x$ & $30-46$ & $1.07(0.013)$ & $0.915(0.03)$ & $0.89(0.02)$ & $0.902(0.08)$ & & $0.744(0.17)$ \\
\hline
\end{tabular}

Summary of maximum LOD scores and the corresponding p-values $(<0.05)$ for linkage regions for alcohol dependence phenotype ALDX2. Results are shown for microsatellites, Affymetrix SNPs and Illumina SNPs. The mean and standard deviation of IC are given for each chromosome. 
Table 4: Summary of linkage results for ALDXI

\begin{tabular}{|c|c|c|c|c|c|c|c|c|c|}
\hline \multirow[b]{2}{*}{ Chr } & \multirow[b]{2}{*}{$\begin{array}{l}\text { Location } \\
\text { (cM) }\end{array}$} & \multicolumn{2}{|c|}{ Affymetrix SNPs } & \multicolumn{2}{|c|}{ Illumina SNPs } & \multicolumn{2}{|c|}{ Microsatellites } & \multicolumn{2}{|c|}{ Comb3 } \\
\hline & & $\operatorname{LOD}(p)$ & IC/Chr & LOD $(p)$ & $\mathrm{IC} / \mathrm{Chr}$ & $\operatorname{LOD}(p)$ & IC/Chr & $\operatorname{LOD}(p)$ & $\mathrm{IC} / \mathrm{Chr}$ \\
\hline I & (138-148) & $1.060(0.014)$ & $0.942(0.02)$ & $1.330(0.007)$ & $0.932(0.02)$ & & $0.832(0.07)$ & $0.950(0.020)$ & $0.972(0.01)$ \\
\hline \multirow[t]{4}{*}{2} & $(10-30)$ & $1.140(0.011)$ & $0.948(0.02)$ & $1.740(0.002)$ & $0.934(0.02)$ & $1.51(0.004)$ & $0.845(0.08)$ & $1.440(0.005)$ & $0.975(0.01)$ \\
\hline & $(114-125)$ & $1.100(0.012)$ & & $0.700(0.040)$ & & & & $1.080(0.013)$ & \\
\hline & (134-147) & $1.100(0.012)$ & & $1.540(0.004)$ & & & & $1.180(0.010)$ & \\
\hline & $(228-252)$ & $1.720(0.002)$ & & & & & & $1.660(0.003)$ & \\
\hline \multirow[t]{2}{*}{6} & $(20-24)$ & $0.810(0.030)$ & $0.947(0.02)$ & $0.660(0.040)$ & $0.935(0.02)$ & & $0.803(0.09)$ & $0.940(0.020)$ & $0.974(0.01)$ \\
\hline & $(183-190)$ & & & $2.150(0.0008)$ & & & & $1.910(0.002)$ & \\
\hline \multirow[t]{4}{*}{7} & $(3-19)$ & $1.350(0.006)$ & $0.944(0.03)$ & $2.3200(0.0005)$ & $0.933(0.02)$ & $0.69(0.04)$ & $0.898(0.05)$ & $1.720(0.002)$ & $0.976(0.01)$ \\
\hline & $(29-37)$ & $1.170(0.010)$ & & $0.760(0.030)$ & & & & $1.060(0.014)$ & \\
\hline & (54-62) & $0.980(0.020)$ & & $0.740(0.030)$ & & $1.22(0.009)$ & & $1.230(0.009)$ & \\
\hline & $(83-119)$ & $\begin{array}{c}2.2500 \\
(0.0006)\end{array}$ & & $1.97(0.0013)$ & & $1.72(0.002)$ & & $\begin{array}{c}2.5200 \\
(0.0003)\end{array}$ & \\
\hline 9 & $(|4|-\mid 42)$ & $0.660(0.040)$ & $0.947(0.02)$ & $0.690(0.040)$ & $0.926(0.02)$ & & $0.782(0.10)$ & $0.770(0.030)$ & $0.974(0.01)$ \\
\hline \multirow[t]{2}{*}{10} & $(122-128)$ & $0.750(0.030)$ & $0.943(0.02)$ & $0.650(0.040)$ & $0.924(0.03)$ & & $0.664(0.08)$ & & $0.967(0.01)$ \\
\hline & $(149-179)$ & $1.9900(0.0012)$ & & $1.750(0.002)$ & & $0.94(0.02)$ & & $1.770(0.002)$ & \\
\hline II & $(117-130)$ & $1.280(0.008)$ & $0.946(0.02)$ & $1.030(0.015)$ & $0.924(0.02)$ & $1.39(0.006)$ & $0.709(0.07)$ & $1.450(0.005)$ & $0.968(0.01)$ \\
\hline \multirow[t]{3}{*}{12} & $(0-5)$ & $1.150(0.011)$ & $0.944(0.02)$ & & $0.929(0.03)$ & & $0.816(0.08)$ & & $0.974(0.01)$ \\
\hline & $(121-125)$ & $0.830(0.030)$ & & $0.78(0.03)$ & & & & $0.800(0.030)$ & \\
\hline & $(167-172)$ & $0.700(0.040)$ & & $0.930(0.020)$ & & & & & \\
\hline 13 & $(81-102)$ & $1.550(0.004)$ & $0.945(0.02)$ & $1.220(0.009)$ & $0.931(0.02)$ & & $0.802(0.10)$ & $1.460(0.005)$ & $0.972(0.01)$ \\
\hline \multirow[t]{2}{*}{17} & $(34-36)$ & & $0.922(0.05)$ & & $0.914(0.03)$ & $1.110(0.012)$ & $0.694(0.08)$ & $0.750(0.030)$ & $0.961(0.02)$ \\
\hline & $(121-123)$ & & & $0.800(0.030)$ & & & & & \\
\hline 18 & $(93-107)$ & $0.960(0.020)$ & $0.940(0.02)$ & $0.720(0.030)$ & $0.918(0.04)$ & & $0.548(0.06)$ & $0.910(0.020)$ & $0.959(0.02)$ \\
\hline$x$ & $(30-46)$ & $2.0500(0.0011)$ & $0.915(0.03)$ & $1.520(0.004)$ & $0.902(0.08)$ & & $0.744(0.17)$ & $1.460(0.005)$ & $0.947(0.03)$ \\
\hline
\end{tabular}

Summary of maximum LOD scores and the corresponding $p$-values $(<0.05)$ for linkage regions for alcohol dependence phenotype ALDXI. Results are shown for microsatellites, Affymetrix SNPs, Illumina SNPs and the combined data (Comb3). The mean and standard deviation of IC are given for each chromosome. Bold text indicate the most significant region on chromosome 7.

level of genome-wide significance. Commonly used resampling-based and gene-drop simulation approaches are computationally intensive and do not lend themselves to the analysis of the large amount of data in this study. We are investigating a more efficient Monte Carlo procedure to assess genome-wide significance in linkage analysis [20].

Our results show that a denser map can be more powerful for linkage analysis. IBD sharing based linkage analysis algorithms usually assume linkage equilibrium between the markers and the strong linkage disequilibrium between closely adjacent markers could potentially introduce false linkage results [21,22]. A study using Affymetrix HMA10K arrays indicated that there was no substantial difference in the results when SNPs in linkage disequilibrium are either retained or removed [15].

This study represents an extensive performance comparison of three different platforms (microsatellite markers, Affymetrix HMA10K Array, and Illumina Linkage III Panel) in a series of linkage analyses for alcoholism. The high density and the robust performance of SNPs make the whole-genome scan a desirable approach for linkage analysis. This new approach may bring a renewed power to IBD sharing based linkage analysis.

\section{Abbreviations}

COGA: Collaborative Study on the Genetics of Alcoholism

ERP: Event-related potential

GAW: Genetic Analysis Workshop

IBD: Identity by descent

IC: Information content

NPL: Nonparametric linkage

SNP: Single-nucleotide polymorphism

\section{Authors' contributions}

$\mathrm{CZ}$ carried out the statistical analysis and drafted the manuscript. SC assembled the Affymetrix linkage data, conducted qualify control and provided useful comments for the study. GL constructed unique genetic maps for all the 


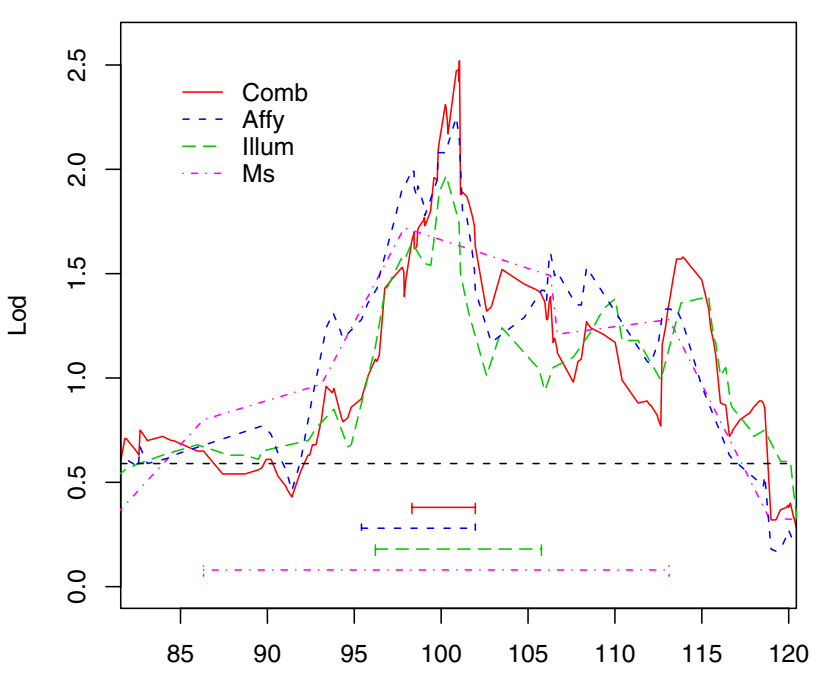

CM

\section{Figure I}

Linkage region on chromosome 7. LOD scores of the linkage region $(83-119 \mathrm{cM})$ for microsatellite markers (pink), Affymetrix SNPs (blue), Illumina SNPs (green) and the combined data (red). Horizontal dashed line is the critical value at point-wise significance level of 0.05 . Bars on the bottom indicate I-LOD intervals for this region in microsatellites (pink), Affymetrix SNPs (blue), Illumina SNPs (green), and the combined data (red).

data sets. MC generated data from the Affymetrix HMA10K array. HG modified MERLIN program to reduce the memory usage. GCK conceived of the study and participated in its design and coordination.

\section{References}

I. Edenberg $\mathrm{HJ}$ : The collaborative study on the genetics of alcoholism: an update. Alcohol Res Health 2002, 26:2।4-2I8.

2. Feighner JP, Robins E, Guze SB, Woodruff RA Jr, Winokur G, Munoz R: Diagnostic criteria for use in psychiatric research. Arch Gen Psychiatry 1972, 26:57-63.

3. Foroud T, Edenberg HJ, Goate A, Rice J, Flury L, Koller DL, Bierut LJ, Conneally PM, Nurnberger JI, Bucholz KK, Li TK, Hesselbrock V, Crowe R, Schuckit M, Porjesz B, Begleiter H, Reich T: Alcoholism susceptibility loci: confirmation studies in a replicate sample and further mapping. Alcohol Clin Exp Res 2000, 24:933-945.

4. Reich T, Edenberg HJ, Goate A, Williams JT, Rice JP, Van Eerdewegh P, Foroud T, Hesselbrock V, Schuckit MA, Bucholz K, Porjesz B, Li TK, Conneally PM, Nurnberger JI Jr, Tischfield JA, Crowe RR, Cloninger CR, Wu W, Shears S, Carr K, Crose C, Willig C, Begleiter H: Genome-wide search for genes affecting the risk for alcohol dependence. Am J Med Genet 1998, 81:207-2 15.

5. Ghosh S, Begleiter H, Porjesz B, Chorlian DB, Edenberg HJ, Foroud T, Goate A, Reich T: Linkage mapping of Beta 2 EEG waves via non-parametric regression. Am J Med Genet B Neuropsychiatr Genet 2003, I I 8:66-7I.

6. Porjesz B, Almasy L, Edenberg HJ, Wang K, Chorlian DB, Foroud T, Goate A, Rice JP, O'Connor SJ, Rohrbaugh J, Kuperman S, Bauer LO, Crowe RR, Schuckit MA, Hesselbrock V, Conneally PM, Tischfield JA, $\mathrm{Li}$ TK, Reich T, Begleiter H: Linkage disequilibrium between the beta frequency of the human EEG and a GABAA receptor gene locus. Proc Natl Acad Sci USA 2002, 99:3729-3733.

7. Jones KA, Porjesz B, Almasy L, Bierut L, Goate A, Wang JC, Dick DM, Hinrichs A, Kwon J, Rice JP, Rohrbaugh J, Stock H, Wu W, Bauer LO,
Chorlian DB, Crowe RR, Edenberg HJ, Foroud T, Hesselbrock V, Kuperman S, Nurnberger J Jr, O'Connor SJ, Schuckit MA, Stimus AT, Tischfield JA, Reich T, Begleiter H: Linkage and linkage disequilibrium of evoked EEG oscillations with CHRM2 receptor gene polymorphisms: Implications for human brain dynamics and cognition. Int J Psychophysiol 2004, 53:75-90.

8. Botstein $D$, Risch $N$ : Discovering genotypes underlying human phenotypes: past successes for Mendelian disease, future approaches for complex disease. Nat Genet 2003, 33(Suppl):228-237.

9. Risch Nj: Searching for genetic determinants in the new millennium. Nature 2000, 405:847-856.

10. Kruglyak $\mathrm{L}$ : The use of a genetic map of biallelic markers in linkage studies. Nat Genet 1997, 17:2 I-24.

II. Kennedy GC, Matsuzaki H, Dong S, Liu WM, Huang J, Liu G, Su X Cao M, Chen W, Zhang J, Liu W, Yang G, Di X, Ryder T, He Z, Surti U, Phillips MS, Boyce-Jacino MT, Fodor SP, Jones KW: Large-scale genotyping of complex DNA. Nat Biotechnol 2003, 2 I : I 233-I 237.

12. O'Connell JR, Weeks DE: PedCheck: a program for identification of genotype incompatibilities in linkage analysis. $\mathrm{Am} J$ Hum Genet 1998, 63:259-266.

13. Abecasis GR, Cherny SS, Cardon LR: The impact of genotyping error on family-based analysis of quantitative traits. Eur J Hum Genet 200I, 9:130-I34.

14. Douglas JA, Boehnke M, Lange K: A multipoint method for detecting genotyping errors and mutations in sibling-pair linkage data. Am J Hum Genet 2000, 66: 1287- 1297.

15. John S, Shephard N, Liu G, Zeggini E, Cao M, Chen W, Vasavda N, Mills T, Barton A, Hinks A, Eyre S, Jones KW, Ollier W, Silman A, Gibson N, Worthington J, Kennedy GC: Whole-genome scan, in a complex disease, using II,245 single-nucleotide polymorphisms: comparison with microsatellites. Am J Hum Genet 2004, 75:54-64.

16. Abecasis GR, Cherny SS, Cookson WO, Cardon LR: Merlin - rapid analysis of dense genetic maps using sparse gene flow trees. Nat Genet 2002, 30:97-101.

17. Kruglyak L, Daly MJ, Reeve-Daly MP, Lander ES: Parametric and nonparametric linkage analysis: a unified multipoint approach. Am J Hum Genet 1996, 58:1347-1363.

18. Kong A, Cox NJ: Allele-sharing models: LOD scores and accurate linkage tests. Am J Hum Genet 1997, 61: I I79-I I 88.

19. Lander ES, Green P: Construction of multilocus genetic linage maps in humans. Proc Natl Acad Sci U S A 1987, 84:2363-2367.

20. Lin $D Y$, Zou $F$ : Assessing genomewide statistical significance in linkage studies. Genet Epidemiol 2004, 27(3):202-2/4.

21. Schaid DJ, McDonnell SK, Wang L, Cunningham JM, Thibodeau SN: Caution on pedigree haplotype inference with software that assumes linkage equilibrium. Am J Hum Genet 2002, 7 I:992-995.

22. Schaid DJ, Guenther JC, Christensen GB, Hebbring S, Rosenow C, Hilker CA, McDonnell SK, Cunningham JM, Slager SL, Blute ML, Thibodeau SN: Comparison of microsatellites versus singlenucleotide polymorphisms in a genome linkage screen for prostate cancer-susceptibility loci. Am J Hum Genet 2004, 75:948-965.

Publish with Bio Med Central and every scientist can read your work free of charge

"BioMed Central will be the most significant development for disseminating the results of biomedical research in our lifetime. "

Sir Paul Nurse, Cancer Research UK

Your research papers will be:

- available free of charge to the entire biomedical community

- peer reviewed and published immediately upon acceptance

- cited in PubMed and archived on PubMed Central

- yours - you keep the copyright
BioMedcentral 
BMC Genetics 2005, 6:S17

Page 7 of 7

(page number not for citation purposes) 